\title{
Era of Robotics
}

\author{
Shuh Jing Ying* \\ Mechanical Engineering, University of South Florida, USA
}

Submission: September 17, 2017; Published: November 21, 2017

*Corresponding author: Shuh Jing Ying, University of South Florida, 4202 Fowler Ave. Mechanical Engineering, Tampa, Florida 33620 USA, Tel: 813-974-5627; E-mail: ying@usf.edu

\section{Editorial}

Science and technology are always progressing, now it is the era of robotics. Many different ways can make robots. The most common robot is mechanical. Mechanical engineering is a major branch in engineering. In the past many transportation tools are the achievements of mechanical engineers. To make it clear, let see a few examples, locomotives, automobiles, ships, airplanes, and even spaceships. Certainly many automations in manufacturing are related to mechanical engineering. Robots are very complicated, they are the products of many disciplines. However mechanical engineer must take the major role in the process. To make it clear I will talk about different robots needed to be built, how these robots to be built and the present status.

Many robots are needed. Let me mention a few below. A test pilot for a newly designed airplane is a dangerous job. It is possible to have a robot to do the job. Fire fighting is a dangerous job. Buildings that are collapsed or burning can trap both first responders and other victims inside. Drones could be built to fly or to drive through small spaces to look for trapped people. Policemen are also at risk. Routine traffic stops, with the wide availability of guns in this country, can escalate to gunfire at any moment. To avoid these dangerous encounters, robots could be deployed by a police to do the routine check-ups. In the recent wars, many military service men and women were injured or even killed because of ground mines. Robots could be deployed here before soldiers. Actually wars are always dangerous for humans to fight, it is possible to use robots to fight, and each solder could control a robot to fight in front for him or her. In this way, the death rate will be greatly reduced. Seniors or disabled persons often need a maid or in-home health service on a daily basis. They also need a companion. A robot may help, and technology is slowly achieving societal expectations. At this moment, humanoid or anthropomorphic robots cannot replicate the skill and emotional support of a care-giver so this is still a challenge. These are just a few examples of ways in which robots may benefits human lives, but we expect many applications to surface with time.
A robot is a multidisciplinary product, including the following major disciplines: mechanical engineering, electrical engineering, computer science, and medical science. Design requires the application of all the fundamental sciences. A good design considers the product from many different perspectives. To make an anthropomorphic robot we must consider the motions of arms, hands, legs, etc. with respect to mechanical engineering principles such as dynamics, mechanics, materials, stress analysis, etc. Furthermore, because of limited space and motor speed, often planetary gear train and harmonic gear train are employed. A good mechanical engineer should have all of these in his or her background. In addition, the need for an intelligent brain in the robot should not be underestimated. The computer and proper software needed to control are becoming exceedingly complex. For these we need engineers in computer science and electrical engineering. Moreover, to make robots really humanistic, we must consider the human form as a model and we need input from medical scientists.

At this moment everything is progressing, however a robot for test pilot is not yet available, but unmanned airplane exists: many different unmanned aircrafts were developed in recent years. For example, one is designed for high altitude flight and powered by solar energy so it can fly for a long time without refuel. Some can carry a bomb and is remotely controlled by a pilot as reported on TV. The unmanned plane or drone is low in speed and has a communication delay so that complex aerial maneuvers are not possible. Certainly, at this moment, a drone cannot function as well as a plane with an on-board pilot. There is a long way to go to reach the goal of robotic test pilot. A robot to replace a firefighter is not available either. However, a remote controlled rover and remote controlled helicopter are available. They can carry a camera or use a claw to help fire fighters to search for trapped people but lack the functionality, durability, and reliability to replace a fire fighter. A robot soldier is not available but mine detectors are available. These detectors are still in development and are not routinely used to clear mine fields. Remote-controlled weapons are also in 


\section{Robotics \& Automation Engineering Journal}

development. They are frequently demonstrated in the news but not used in the battlefield. Machine guns or rifles are mounted on a vehicle with a remote controller and can be fired when the controller sees an enemy in sight. So the future wars fought by robots is possible. A real robot maid or care-giver does not exist, but many simple functions such as mechanical arm and hand are available. Robot-assisted living is a very interesting subject, many people are working on it. Robot even is used in agriculture field in China.

We humans have a vestibular system in our ears to sense the balance of body in vertical position. Similarly, gyroscope has a special property to keep the rotation in steady state, say vertical position. It will sense the deviation from the vertical position. This property has been used in power wheel chair. Walking is so essential for every human being to do. But it is difficult for a robot to do. At this moment humanoid robot walking is existing but it is to be improved. It can only walk in small steps and with low speed. Many scientists are working on this subject. I think that one possible solution is to have a gyroscope sensing device to control the motion of legs Robot vision is another interesting subject to study, at this moment 3-d vision has been developed and actually applied to unmanned helicopter to detect the overhead power cable as a visual guide to fly Also 3-d stereo vision is used for nursing robot (mechanical device) to take care of elderly. From 3-d stereo vision of nose and mouth, the robot can easily recognize who is the elderly person to be served. Interactive is a very hot subject to pursue. Early stage development up to the year of 2015 in the interactive communication is well covered by the report by Mavridis. However, in view of recent development of 'Dragon', computer can type words by voice commands. And I Phone 7 can accept voice commands to give out information. With a minor modification, robots can accept voice commands and carry out tasks as a real maid is possible in the near future. All of these projects mentioned above are in the development stage, so there is lots of work waiting to be done. We have lots of work to do.
Your next submission with Juniper Publishers will reach you the below assets

- Quality Editorial service

- Swift Peer Review

- Reprints availability

- E-prints Service

- Manuscript Podcast for convenient understanding

- Global attainment for your research

- Manuscript accessibility in different formats

( Pdf, E-pub, Full Text, Audio)

- Unceasing customer service

Track the below URL for one-step submission https://juniperpublishers.com/online-submission.php 